\title{
Deferred Utterances and Proper Contexts
}

\author{
Marco Ruffino \\ Federal University of Rio de Janeiro and LanCog Group \\ BIBLID [0873-626X (2012) 34; pp. 807-822]
}

\section{Proper contexts}

Frege (1918-1919) famously makes a caveat concerning his doctrine of sense and reference: there are some special expressions like 'here', 'today' and 'that', that cannot by themselves express senses (and, therefore, cannot have references). Something else is necessary, namely, the extra-linguistic context in which the particular tokens of words of this kind occur. Therefore, in order to grasp the sense (and, therefore, the reference) expressed by an utterance containing some of these expressions in a particular context we need to know some facts about the latter (e.g., the place where a particular token of 'here' occurs, the day when a particular token of 'today' occurs, the demonstration that accompanies a particular token of 'that', etc.).

These expressions are what we nowadays call indexicals, and although several philosophers now reject Frege's thesis that they have a (Fregean) sense in a context, almost everyone retains the spirit of Frege's remark that the semantic value of indexicals (i.e., their reference or extension) depends on the context of occurrence. Moreover, almost everyone takes the semantic value of an indexical to be some element present in the context of occurrence (the day of occurrence, in the case of 'today', the utterer, in the case of 'I', the location, in the case of 'here', etc.). Different indexicals take different elements of the context of utterance (the agent, the location, the time, the addressee, etc.) as semantic value. And the semantic behavior of each indexical is governed by a rule or function that assigns a particular semantic value to each context of utterance. Following Kaplan, most philosophers call this function the character of the indexical, and the 
semantic value assigned by the character in a particular context is called the content of the indexical in that context. The character is the same in all contexts, but the content might change.

Kaplan presented his theory of the semantic behavior of indexicals in his classical "Demonstratives" (Kaplan 1989), and his theory was widely accepted, to the point of becoming a kind of established view for quite a long time. One of Kaplan's thesis is that, broadly speaking, there are two sorts of indexicals: those that normally require an accompanying demonstration (typically a pointing) when placed in a context, and those that do not require such a demonstration. The first kind of expressions Kaplan calls demonstratives, and the second he calls pure indexicals. Examples of demonstratives are 'this', 'that', 'he', 'there', etc. (a demonstration is needed to make clear which of the objects in the context the speaker has in mind as the demonstratum); some examples of pure indexicals are 'I', 'now', 'here', 'today', etc. (no demonstration is required).

According to Kaplan's theory, pure indexicals have a special property: if they occur in a context c, they are guaranteed to have a semantic value simply in virtue of the constitutive elements of c, i.e., the speaker, the location, the time of utterance and the possible world in which c occur. This depends, of course, on what we take a context of utterance to be. In Kaplan's work we find a highly technical (and somewhat simplified) notion: a context includes an agent, a location, a time, and a possible world ${ }^{1}$ (i.e., a world in which the utterance takes place). One important feature of Kaplan's notion of context is that its constitutive elements are always those of the production of the utterance (i.e., the agent of the context is the agent that produces ${ }^{2}$ the utterance, the place of the context is the place of

${ }^{1}$ For this reason, we should probably consider 'actual' as a pure indexical as well: it has the possible world of the context of utterance as semantic value.

${ }^{2}$ As Perry (1997, pp. 592-3) notices, although utterances generally involve tokens, they are not always identical with the act of producing them. The agent of an utterance is not necessarily the one that produces the (written or spoken) token. In the same way, the location and time of the utterance is not necessarily the location and time in which the token is produced. The same token might be used in several different occasions (or by several different agents) to produce different utterances. For instance, someone might use a note 'Will be back soon', written by someone else, and leave it at the door of his office at different times 
utterance, the time of the context is the time of the utterance, etc.)

If we think of contexts as combinations of constitutive elements (a time, a location, an agent and a possible world), we can raise the question of which of these combinations are admissible for utterances. Any combination of agents, locations, times and possible worlds is admissible? If the agent, the location, the time, and the possible world of the context are those in which the utterance is produced, then there seems to be a restriction on admissible contexts, since not just any combination of these elements are appropriate contexts for utterances. E.g., a context in which the agent is not at the location or at the time in which the utterance takes place. Thinking about these odd combinations of elements, Kaplan famously advocates their exclusion from the class of admissible contexts and a restriction to what he calls proper contexts:

What has gone wrong? We have ignored the special relationship between 'I', 'here', and 'now'. Here is a proposed correction. Let the class of indices be narrowed to include only the proper ones-namely, those $<_{w}, x, p, t>$ such that in the world $w, x$ is located at $p$ at the time t. Such a move may have been intended originally since improper indices are like impossible worlds; no such context could exist and thus there is no interest in evaluating the extensions of expressions with respect to them. (Kaplan 1989, p. 509)

One of the efects of this restriction is that some sentences like

(1) I am here now.

come out true in any context, for in any proper context, the agent of the utterance is at the location of the utterance at the time of the utterance. (Only in improper contexts the agent might not be at the place or time of the utterance; but improper contexts are rendered irrelevant by the restriction.) A sentence that yields a true proposition in any context is a logical truth, according to Kaplan's definition.

Something interesting about (1) is that, although it is logically true, the proposition it expresses in a context is not a necessary truth. If (1) is uttered by me in Lisbon on July $9^{\text {th }} 2010$, it expresses the true proposition that M.R. is in Lisbon on July $9^{\text {th }}$ 2010, but the latter is of course only contingently true. (Maybe there are other sentences 
that are not logically true by the standard definition, but that come out as logically true if only proper contexts are allowed.) Something important in Kaplan's approach is that, by restricting the contexts to proper context, the context that is taken together with a sentence in order to produce a proposition is always the one of the production of the utterance. Therefore, the restriction to proper contexts implies that the semantic value taken by pure indexicals will be elements of the context in which the utterance occurs.

In this paper I'll be referring to this as Kaplan's view, but of course Kaplan is not the only one who thinks along these lines. I call it this way because Kaplan was one who clearly saw the alternatives, and explicitly and deliberately restricts contexts of utterances to proper contexts. Other influential philosophers like Montague, Lewis, Prior and Perry, to mention a few, also think that the semantic value of indexicals are taken from the context (or index) of the utterance.

Despite its intuitive appeal, Kaplan's view on this topic was challenged by some philosophers of language, based on the presentation of equally intuitive cases of utterances recorded or written in one context, but meant to be read (or decoded) in another context, i.e., at a different time, or at a different location, or uttered by a different agent. Most notably, Predelli (2005) argues that we are in many important ways free to shape the context adequate to represent an utterance, and there is no commitment either to the agent that produces the utterance, or the time or location in which the utterance takes place, or even to the possible world in which it takes place. In this paper, I shall first review these objections. Then I shall argue that these examples can be more naturally accommodated within Kaplan's theory by sharply distinguishing between a theory of semantic content from a theory of speech acts: Kaplan's approach yields an explanation of the semantic content of an utterance (which might be false) and a pragmatic theory (including, among other elements, Grice's pragmatics of implicatures) yields an explanation of how speakers can transform this semantic content into another (possibly true) content. 


\section{The puzzle}

The phenomenon that I want to focus now, and that is sometimes regarded as an exception to Kaplan's theory, was first mentioned in print by Kaplan himself in a footnote (Kaplan 1989, p. 491, footnote $12)$, in which he notices that, in recorded messages for later reproduction, we find a use of 'now' that doesn't seem like a case pure indexical. E.g., the spoken message

(2) I am not here now.

recorded in an answering machine, and meant to be reproduced at different times. In cases like this, according the semantic value of 'now' doesn't seem to be the time in which the message is encoded (recorded or written), but rather the time in which the message is decoded (listened to or read).

I shall call deferred those written or recorded utterances employing 'now' or other pure indexicals that are meant to be read or listened to at a different time, place, etc. from that of the writing or recording. I mean deferred in a very broad sense (and not just in the temporal sense), i.e., an utterance is deferred if it is encoded in one context, but meant to be decoded in another context that differs from the original one in an aspect that is semantically relevant for some pure indexical employed in it. Deferred utterances seem to present a puzzle for Kaplan's theory: 'here' and 'now' are pure indexicals and, as such, must take as semantic values the place and time of the context in which the utterance is produced. However, this does not correspond to be the intuitive understanding of (2). How can one account for the intuitive understanding of (2) and also preserve the purely indexical nature of 'here' and 'now'?

Following a suggestion made by Donnellan, Kaplan briefly mentions in the same footnote the possibility of there being two different forms of 'now' in natural language: one that takes as reference the time when the utterance is produced, and the other that takes the time when the utterance is decoded. Let's represent both uses of 'now'. Suppose that (2) is recorded at $t_{0}$, and is decoded (i.e., heard or read) at $t_{1}$. The first use of 'now' takes $t_{0}$ as semantic value. The utterance is false (and under this reading, it cannot come out true). But the second use of 'now' takes $\mathrm{t}_{1}$ as semantic value, and (2) 
might be true (e.g., if the speaker is not at the place in which (2) is played or read in $\mathrm{t}_{2}$ ). ${ }^{3}$ However they may differ, both uses seem to have something in common, i.e., they do not need an accompanying demonstration. They automatically take some constitutive element of the context as semantic value (the time of recording or the time of decoding). So there is a sense in which they are both pure indexical uses. For brevity, I will refer to these uses as purely indexical-c (which takes the coding time as semantic value) and purely indexical$\mathrm{d}$ (which takes the decoding time as semantic value), respectively.

Kaplan also mentions possible demonstrative uses of 'here' (besides the purely indexical use). One can, e.g., point at a location in a map, and say

(3) In two weeks I will be here.

I suppose that we could have something similar for 'now'. E.g., suppose that in a history lecture videotaped for future exhibitions, there is a line in the blackboard representing the chronological order of the events of the Second World War, and the teacher indicates a point of the line and says

(4) Only now the US enters the war.

In this use, 'now' requires an accompanying demonstration (different demonstrations of the line yielding different semantic values). This use is different from pure indexical-c and pure indexical- $\mathrm{d}$ above, in that simply mentioning the word 'now' won't do. A pure indexical-c reading of 'now' would have (4) saying that at the time of the videotaping the US entered the war, which is most likely false (supposing that it was videotaped long after 1941). And a pure indexical-d reading would have (4) saying that at the time in which the tape is played the US entered the war, which is also false. In this intended use of 'now', the demonstration is required.

One could think that the recognition of a demonstrative use of 'here' and 'now' would solve the puzzle, i.e., 'here' and 'now' normally work as pure indexicals, but in deferred utterances they have a demonstrative use. However, as Sidelle (1991) notices, demonstra-

\footnotetext{
${ }^{3}$ Multiple uses of (2) at times t2, t3, etc., presumably would pick t2, t3, etc., as semantic values.
} 
tive occurrences of 'here' can, in principle, be replaced by 'there'. (Maybe something similar can be said for the demonstrative use of 'now', i.e., that it is replaceable by 'then'.) In the case of recorded messages, however, it does not seem right to replace (2) by

(5) I am not there now.

Therefore, what we have in the case of a recorded message is, in general, not a demonstrative use of 'here' (or now). In other words, the problem represented by utterances of (2) does not depend on the attribution of a strictly pure indexical working to 'here' and 'now'. That is to say, even if we admit of non-indexical (demonstrative) uses of 'here' and 'now', the puzzle still remains.

\section{Some alternatives}

There are three amendments to Kaplan's theory that I want to consider here. None of them seems to me to be adequate, for different reasons. The first amendment is suggested by Sidelle (1991) as a solution to what he calls "The Answering Machine Paradox". According to this view, there might be (and in (2) we have such a case) what Sidelle he calls deferred utterance (he uses the term in a different way than I do $)^{4}$, i.e., utterances in which the agent is not at the place or at the time when it occurs. Therefore, according to his view, it is not necessary for the agent of an utterance to be at the place (or time) of the utterance. According to Sidelle's proposal, when the agent records the message, he is not making an utterance at that point; he is merely arranging things so that an utterance (or maybe many of them) will be made later, at the time when someone calls the agent's machine (and the agent supposedly won't be there at the time when the utterance takes place). This seems to imply the denial of one of the principles behind the puzzle, which I will call Principle L:

(L) The utterer is always located at the time and place of the ut-

${ }^{4}$ It will become clearer in the last Section of this paper that Siddele's use of the term differ from mine in a subtle but important way. He means that no utterance is actually made when the utterer encodes it, but only when the listener (or reader) decodes it. I mean that an utterance (the same one) is made in both contexts. 
terance.

(L) appears intuitively correct, and it is certainly part of the motivation for Kaplan's restriction of contexts to proper ones. But Sidelle thinks that it should be rejected, and he offers two reasons for this, none of them very compelling in my view. The first reason deals with (L) itself. According to Sidelle,

[A]ll (or at least, almost all) of the sorts of utterance situations we are familiar with involve a speaker's being located at the place of his utterance. The general claim here [L] would just be an extrapolation which is perhaps not very imaginative- one, in particular, which did not focus very clearly or much on answering-machines or scraps of paper left on kitchen tables (1991, p. 534)

Sidelle's claim seems to involve some circularity; for it challenges our right to extent to messages left on answering machines and scraps of paper left on the kitchen the same account that is provided for normal utterances. This presupposes that in the latter cases, we do have something deeply different going on. But this has to be explained independently, that is to say, we need some independent reason for believing that cases like this are an exception. It is not enough to raise the vague and general doubt concerning our right to assimilate the latter cases to the former ones. Sidelle's second reason for abandoning (L) is more general, and challenges the broader claim that an agent must be located at the place where the action occurs:

[W] a least allow ourselves to talk in ways which don' $t$ accord with this general claim. For instance, after putting some clothes in a washing machine, I might run into someone at the supermarket and tell them that I 'm doing my laundry (now). It would be most unusual for them to say that I can't be, since I'm not currently located by a washing machine. (1991, p. 534)

I think that examples like this bring very little support to Sidelle's claim; it seems clear to me that in the envisaged situation, 'I am doing my laundry' means that I am in middle of a somewhat complex process, which involves running to the washing machine every now and then to perform some actions that do require my presence there, and sometimes require (or allow for) my presence at the supermarket, e.g., to buy some more laundry soap. The same with 'I am finishing my PH.D. at UCLA': the fact that I am not physically on campus all the time hardly shows that I might perform an action that takes place 
at UCLA without being there. The proper description of my action is that I am in a process which involves several different kinds of actions, each one of them requiring my presence, sometimes on the UCLA campus, sometimes at home (reading and writing). To sum up: in cases like those that Sidelle has in mind as counter-example to the broader thesis that underlies (L), i.e., in which the agent does not seem to be at the place where the action takes place, what most likely is going on is that the action is being misdescribed.

The second amendment is proposed, among others, by Colterjohn and MacIntosh (1987), who suggest that pure indexicals occurring in deferred utterances like (2) contain a sort of "proxy finger" indicating the time and the location in which the message is decoded. In the same spirit, Smith (1989) proposes a view according to which indexicals might have multiple characters, sometimes working as pure indexicals, sometimes working as demonstratives, and sometimes working as neither of them. For instance, the 'now' in (4) is not working according to an indexical or demonstrative rule for him, but according to what he calls the "historically emphatic" rule. (I suppose that he means by that the role of capturing a certain time that is contextually relevant, and different from the time of utterance.) Smith sees a kind of "super-rule" or what he calls a "metacharacter" governing the use of an indexical, that associates to that indexical the character appropriate to each context.

As Predelli points out (2005, pp. 48-9), there are some problems with this kind of proposal. First, regarding Colterjohn and MacIntosh's suggestion, the proxy finger is supposed to demonstrate whichever place the note is read (or listened to), but clearly many such places are not the ones that the utterer had in mind (and certainly not what the reader understands by reading the note). E.g., if (2) in a written note is carried by the wind and ends up in my neighbor's house, and if someone finds the note and reads it there he should, according to this proposal, understand that 'here' means my neighbor's house, which doesn't seem right. Second, as Predelli also correctly points out, Smith's metacharacters remain a rather mysterious semantic entities, and appealing to them looks rather like a strategy for masking the arbitrariness of characters changing from context to context. The character of an indexical is normally supposed to be a simple rule that, at least in principle, encodes once and 
for all the semantic value that it should have in all different contexts. But it is hard to see anything like a general rule corresponding to the metacharacter, especially if, as a result of new devices like the answering machine, there are new characters that an indexical might have that were not foreseen.

I follow Predelli in considering the alternatives to Kaplan's view reviewed so far as unsatisfactory. For the rest of this section I will consider the amendment proposed by Predelli himself, and I will argue that it is unsatisfactory as well. His proposal is, in a way, more "conservative" than the previous ones, since it preserves the spirit of Kaplan's original approach, but at the cost of adopting a very liberal view on the notion of the intended index of an utterance. According to this proposal, indexicals always take their semantic value from an index together with which they are to be interpreted. "Index" is a technical notion, and it resembles Kaplan's notion of context: an index typically includes an agent, a location, a time, and a possible world. In Kaplan's view, as we saw, the context is always the one in which the utterance takes place, i.e., the agent, location, time and possible world in which the utterance is produced. I'll refer to the index formed by the agent, location, etc., of the utterance as the index of utterance. According to Predelli, whenever a speaker's utterance includes an indexical expression, a correct interpretation of the utterance must recognize that there is an intended index together with which the indexical should be taken into account, and the intended index might be different from the index of utterance. And he thinks that this explains many utterances that are intuitively true, but that would be false if taken according to Kaplan's original view. E.g., when telling someone a story involving three fictional characters A, $\mathrm{B}$ and $\mathrm{C}$, and a fictional murder, I might say

(6) A thought all the time that B was the murderer, but actually $\mathrm{C}$ was the one who did it.

Now what is the semantic value of 'actually' in (6)? The real actual world? If so, my utterance is certainly false, for $\mathrm{C}$ is not a murderer in the actual world. Predelli thinks that it is natural to take the semantic value of 'actually' as being the world of the story. The same happens, e.g., in a history class about Napoleon's fate in Waterloo, when the teacher, trying to present Napoleon's situation in a dra- 
matic way, speaks in the first person:

(7) What should $I$ do now?

What is the semantic value of 'I' and 'now' here? If we take the index of utterance as the relevant one, the 'I' refers to the teacher, and 'now' to the time of the class. However, it is clear that the teacher was trying to say something about Napoleon in June $18^{\text {th }}$, 1815. Hence, according to Predelli, in order to correctly represent the intended utterance, we should rather take as index one that has Napoleon as agent and June $18^{\text {th }}, 1815$ as time. This is the one that the speaker had in mind in making the utterance, and the hearer can only understand the utterance if he realizes that.

In the example of the answering machine, the speaker, when recording the message, has in mind a certain index against which the message should be decoded, or, better, a set of indexes (i.e., any future instant in which the agent is not at home). The listener, in order to understand what the speaker said, has to grasp what the intended index is (supposedly, the time is the one of the phone call).

I do not find the alternative view here presented quite convincing. Most of the examples can be seen either as cases of anaphora (i.e., in the case of 'actually' in (6), it can be seen as anaphoric on the possible world described at the beginning of the report (the fictional world)), or cases in which we can plausibly see the original utterance as false but pragmatically implying a true one. (I will elaborate the latter point in the last section.) But the main obstacle for abandoning the restriction to proper contexts comes from considerations concerning the very special epistemic roles that beliefs described by pure indexicals seem to have, i.e., beliefs that one express using 'I', 'here' and 'now' (and possibly 'actual'). I can only offer here a very brief sketch of the considerations that are relevant in this connection, since a full account would require a much deeper incursion into the philosophy of mind. On the one hand, there seems to be a deep and somehow fundamental relation between the epistemic states that are expressed using pure indexicals, i.e., between those states of mind corresponding to beliefs regarding who one is, where one is, and when it is. This is, as we recall, Kaplan's main motivation for placing the restriction to proper contexts: he wanted to capture a connection between the semantic rules of 'I', 'here', 'now' (and perhaps 
'actual'). The proposed revision seems to ignore, or at least to dramatically play down the relevance of this connection. On the other hand, the beliefs in question seem to play a very special role in one's total cognitive state, and are central for the believer's orientation in the world as a person and as an agent. This is part of Perry's point in calling "locating beliefs" those concerning where one is, when it is, and who one is (Perry 1979). Beliefs of this sort place the believer in a special state of mind and have motivational force that other (nonindexical) beliefs do not seem to have. Suggestions such as Predelli's, in which we are largely free to chose the context that better suits an utterance seems to miss (or at least to diminish to the point of rendering them irrelevant) the important epistemic and motivational force that these indexicals seem to have.

Maybe a better strategy, one that preserves the important epistemic roles and connections between locating beliefs would be to leave them and their contexts where they are, and look for variations in the pragmatic implications that people may draw from a proposition expressed using indexicals. There certainly is a role to be played by the speaker's intention in recording (2) or in uttering 'I will invade Russia' (in a history class). But maybe a better way of accounting for this intention is not to take the speaker's intention as playing a semantic role, but a post-semantic role ${ }^{5}$, i.e., once every semantic value is fixed, one still has to read somehow the speaker's intention in order to draw the right conclusion from the semantically expressed proposition.

\section{Back to Kaplan's original view}

In this section I will sketch my proposal for dealing with deferred utterances, which holds on to Kaplan's idea that the semantic value of indexicals are always taken from the context in which the utterance is produced, and which I will call the natural view. ${ }^{6}$ It is, therefore,

\footnotetext{
${ }^{5}$ I am using Perry's terminology (Perry 1998).

${ }^{6}$ Predelli calls it the "simple minded view". This designation is clearly biased, and it is hard to believe that the great founders of formal semantics would have been really simple minded at any point.
} 
somewhat more "conservative" than Predelli's. ${ }^{7}$

Utterances like (2) are systematically false, but I see a divorce between what is semantically expressed by (2), and what the caller learns (i.e., a true proposition) when he hears (2). Here is a sort of consideration that, I think, supports this point of view. There seems to be a difference in our understanding of (2) recorded in an answering machine while it is being actually used as an answering machine, and when it is not being so used anymore. Imagine the situation in which there is an old recording of (2) as a greeting message left over 30 years ago by John in his old answering machine. But he has passed away some years ago, and that machine is no longer in use for answering phone calls since his widow bought a new and modern machine and recorded her own new greeting message. But the widow likes to play the old recording sometimes anyway just to hear her late husband's voice and remember the old happy days. It doesn't seem that, in this situation, the widow will take the playing of (2) as a true utterance made by the recorder, since the husband is not there anymore.

What happened? Why is it that the same message was apparently taken to be true during the many years that it was in use in the old machine(while John was alive) and now is no longer taken to be true, but is rather seen as a souvenir of John's life? (What the widow will probably think is that the recording was made at a certain place and at a certain moment in the past, and that John was certainly saying something false when he recorded (2), but which was used for the purpose of communicating true propositions for many years. What I think is going on here is that the semantic content of (2) is always the same, during the years of use and now, i.e., that John was not at the time and place when the recording took place, which is certainly false. But the false proposition was used (during the useful lifetime of the answering machine as an answering machine) to convey many true propositions, i.e., that John wasn't home whenever someone tried to

\footnotetext{
${ }^{7}$ I should remark that, as mentioned before, this proposal is not apparently the one that Kaplan himself favors in the footnote where he raises the problem (1989, p. 491, footnote 12). Although his remarks are very brief and no systematic theory for deferred utterances is elaborated in them, Kaplan seems inclined to see a pure indexical in written and recorded messages as being actually ambiguous between what I called in Section II a pure indexical-c and a pure indexical-d.
} 
reach him during his absence. That is to say, what was decisive for taking (2) as conveying a true or a false proposition was not the semantic value of (2) itself, but the purpose for which it was employed (heard or read). In other words, what was essential was not the semantic value of (2) but, as we may call, the speech act for which it was used as a vehicle.

The same consideration could be raised concerning Smith's many character view, and in particular Colterjohn and MacIntosh's formulation of it. According to the latter authors, the note containing the indexical 'now' or 'here' works as a sort of "proxy finger" that indicates the place where the note is (or the time in which it is read). But suppose that we read the note a very long time after it was written (say, the note is exposed in a museum together with someone's writings and personal belongings). We don't take the 'here' or the 'now' in the note to refer to the museum or the present time; we see it rather as a biographical information about someone's life.

Someone thinking along the lines of Predelli's proposal could reply that, in this situation of reading or listening the message long after it was produced (and we do not take the indexical to refer to the place or time in which the message is read or listened), what happens is simply that the person who recorded or wrote it had some appropriate index (or a collection of appropriate indexes) in mind, and we are able to recognize that the present index is not one of them. But is this really so? The person who left the message in the machine seems to have in mind any future moment in which someone calls and she is not at home. Is there an intended time limit for the future indexes? The time limit is certainly a pragmatic matter; but this does not necessarily have to do with the proposition semantically expressed by the note. In order to know this proposition, we need some information regarding the situation in which it was written or recorded. But even if we do not exactly know what the original proposition was (e.g., that John was not at home at the time when the message was recorded, which is presumably false), we are able to derive, by pragmatic rules, the proposition that really matters in the present situation, i.e., that John is not home right now, at the time when we are calling him.

Something analogous can be said for another example discussed in the literature and normally presented as a counter-example to Ka- 
plan's thesis. The example is:

(8) I exist.

According to Kaplan's theory, all occurrences of (8) are true because in every proper context the agent must exist, although the truth it expresses is, of course, a contingent one. This renders all occurrences of

(9) I no longer exist.

false. However, according to some critics (e.g., Predelli (2005, pp. 45-6)), true instances of (9) might occur, e.g., as part of one's will (meant to be read after the agent of the utterance has died).

Now, intuitively, if (9) is part of one's will, and if it is read short after one's death, it might be taken as conveying something true (e.g., if it is something like 'I no longer exist; since I have no living relatives, please donate all my money to charity'.). But suppose (9) appears in a will exposed in a museum of someone that died a thousand years ago. In this situation, I think it is less natural to take (9) as expressing something true. We tend to take (9) in this situation rather as a document about one's life, i.e., about what he did or thought many centuries ago. Again: what happened? If (9) expressed a true proposition right after the agent's death, it should continue to express a true proposition at any future time, but we hardly (or much less naturally) take it that way. What I think is going on is that when we look at one's will right after his death, and again many centuries later, what changes is the purpose of reading (9), and therefore the kind of proposition that we might pragmatically infer from one and the same (false) proposition expressed by (9), i.e., that that man did not exist at the time when the will was written.

If this is correct, Kaplan's original view and the corresponding restriction to proper contexts does not need to be revised. There is certainly something correct in the following complaint that Predelli formulates against Kaplan's view:

It follows from the Simple-Minded View [...] that 'I am not here now' may never be uttered/written truly. But this clashes with our intuition that there are true instances of 'I am not here now', written on a scrap of paper or reproduced by a recording device. An analogous difficulty is raised by utterances of 'I exist (now)'. Given the thesis that ' $\mathrm{I}$ ' and 'now' refer to the utterer and the time of utterance, together with [the 
thesis that] a speaker exists at the time of utterance (or inscription), it follows that 'I exist (now)' may not be uttered or written falsely. But this conclusion is also at odds with our intuitions concerning certain instances of written notes and recorded messages. For instance, 'I do not exist any longer' may well occur truly as part of one's will. (2005, pp. 45-6)

Predelli (and other critics) are right in that there is a clash with our intuition at some point, but the diagnosis proposed is, in my view, misleading. What we need to do is simply to recognize that the semantically expressed proposition might be taken for different purposes in different contexts, and therefore the pragmatically inferred proposition will be different. We might have the same false proposition expressed many times and in different contexts by reproducing the vehicle (note or recording) of the original utterance, but each time a different (and maybe true) proposition is inferred. ${ }^{8}$

\section{Federal University of Rio de Janeiro and LanCog Group}

\section{References}

Colterjohn, J. and MacIntosh, D. 1987. Gerald Vision and Indexicals. Analysis 47: $58-60$.

Frege, G. 1918-1919. Der Gedanke. Eine logische Untersuchung. Beiträge zur Philoophie des deutschen Idealismus III, pp. 36-51.

Kaplan, D 1989. Demonstratives. An Essay on the Semantics, Logic, Metaphysics and Epistemology of Demonstratives and Other Indexicals. In Themes From Kaplan, ed. by Almog, J., Perry, J., Wettstein, H. New York: Oxford University Press.

Perry, J. 1979. The Problem of The Essential Indexical. Noûs 13: 3-31.

Perry, J. 1997. Indexicals and Demonstratives. In A Companion to the Philosophy of Language, ed. by Hale, B. and Wright, C. Oxford: Blackwell.

Perry, J. 1998. Indexicals, Contexts and Unarticulated Constituents. In Proceedings of the 1995 CSLI-Amsterdam Logic, Language and Computation Conference. Stanford, CA: CSLI Publications.

Predelli, S. 2005. Contexts. Meaning, Truth and the Use of Language. Oxford: Oxford University Press.

Sidelle, A. 1991. The Answering Machine Paradox. Canadian Journal of Philosophy 21: $525-39$

${ }^{8}$ A previous version of this paper was presented at the 1rst Annual Workshop Language, Mind and Cognition, in July 2010, in Lisbon. I thank the audience for many criticism and suggestions for improving the text. I also thank CNPq (Brazil) for the research grant that supported my work for this paper. 